\title{
Differences between queen piping temporal structures of two honeybee species, Apis cerana and Apis mellifera
}

\author{
Tetsu YAmamoto $^{1}$ (D) Michio Sugahara $^{2}$, Ryuichi OKadA ${ }^{2}$, Hidetoshi Ikeno ${ }^{1}$ \\ ${ }^{1}$ School of Human Science and Environment, University of Hyogo, 1-1-12 Shinzaike-honcho, Himeji, Hyogo 670-0092, \\ Japan \\ ${ }^{2}$ Graduate School of Science, Kobe University, 1-1 Rokkodai, Nada-ku, Kobe, Hyogo 657-8501, Japan
}

Received 14 July 2020 - Revised 14 December 2020 - Accepted 1 January 2021

\begin{abstract}
In swarming season, honeybee queens emit two kinds of queen piping signals: tooting and quacking. These signals are considered to be important for swarming, and honeybees distinguish between the two signals through differences in their temporal structures. In this study, we revealed that the piping signals of two honeybee species, Apis cerana and Apis mellifera, had different temporal structures. The tooting of A. cerana consisted of almost one long syllable, while that of $A$. mellifera was constructed from several syllables. The quacking of both species comprised around 50 short syllables, but the duration and period of the syllables of A. cerana were about half those of $A$. mellifera. The findings provide new insights that reveal the mechanisms of signal discrimination and the functions of the signals.
\end{abstract}

\section{Apis cerana / Queen piping / Communication / Swarming / Vibroacoustic}

\section{INTRODUCTION}

Social insects such as bees and ants use vibrations and airborne sounds as methods of communication (Kirchner 1997; Hunt and Richard 2013; Hepburn et al. 2014). These vibroacoustic communications are very important, especially for cavity-nesting honeybees such as Apis cerana and Apis mellifera, which live in dark hollows. Worker bees use many kinds of vibroacoustic communication related to foraging and swarming (Kircher 1993; Seeley and Tautz 2001; Schneider and Lewis 2004; Hrncir et al. 2005; Nieh 2010; Seeley et al. 2012; Tan et al. 2016). Queen bees also perform vibroacoustic communications, called queen piping, in the swarming season when new queens emerge, that were first described

Corresponding author: T. Yamamoto, tetuhome.yamamoto@leto.eonet.ne.jp Michio Sugahara is deceased Handling Editor: David Tarpy more than 200 years ago (Huber 1792). Although the mechanisms for triggering the preparation of swarming have not been fully described, several factors are known to induce a colony to prepare to swarm (Winston 1987; Grozinger et al. 2014), for example, colony size (comb area, worker population), brood nest congestion, worker age distribution (high population of young workers), reduced transmission of queen pheromones, and resource abundance (nectar, pollen). When a colony begins to prepare for swarming, worker bees construct multiple (5-20) queen cells (specially shaped, downward-facing cells for rearing queens) and rear new queens (Winston 1987; Grozinger et al. 2014; Smith et al. 2014). Before a new queen emerges from her cell, many workers (about half of all workers) and the mother queen leave the nest in a "prime swarm." On the same day or a few days later, a new queen emerges, and several days after that, some of the remaining workers may leave the nest with a newly emerged virgin queen 
in a secondary swarm (an "afterswarm"). This swarming behavior involving virgin queens may be repeated several times (Winston 1987; Seeley and Tautz. 2001; Grozinger et al. 2014). After that, the emerged queen, who remains in the nest, kills the other queens in the cells. If another queen emerges, the remaining queen and the newly emerged queen fight until one dies (Winston 1987; Gilley and Tarpy 2005), and the surviving queen takes over the parental colony. Queen piping is performed from after the prime swarm to the end of the final afterswarm (Michelsen et al. 1986; Grozinger et al. 2014). These phenomena, swarming and emitting queen pipings, occur in both species, A. mellifera and A. cerana.

Young queens produce two kinds of queen piping signals (Huber, 1792): tooting and quacking. Tooting is emitted by a queen who has newly emerged from her cell, whereas quacking is used by queens who are confined to their cells. The production, transmission, and biological significance of the signals have been studied in A. mellifera. Queens generate the piping signals by vibrating their flight muscles (Kirchner 1997; Hrncir et al. 2005); the signals are transmitted through the air and substrates in the nest and can be observed as substrate vibrations and airborne sounds (Kirchner 1997; Hrncir et al. 2005; Hunt and Richard 2013). The following phenomena and hypotheses of queen piping have been reported. The tooting signal frequently induces the quacking signal (Michelsen et al. 1986; Kirchner 1997); it also freezes worker movements and causes a delay in the emergence of confined queens (Fletcher 1978; Bruinsma et al. 1981; Grooters 1987; Gilley 2001). Furthermore, queens who emit tooting very frequently tend to kill many more rivals and survive longer (Schneider et al. 2001; Schneider and DeGrandi-Hoffman 2003; Long et al. 2017). A confined queen emits quacking and recruits workers to protect her cell from a tooter (Kirchner 1993). Moreover, Visscher (1993) argued that a tooter may use quacking to evaluate the number and strength of her competitors and, thus, the risk of fighting and taking over the colony instead of leaving with an afterswarm. These studies showed that queen piping may have an important biological role in swarming, but this has not yet been fully clarified.
The acoustical properties of queen piping signals of $A$. mellifera have also been studied for many years. Woods (1956) developed a sound recording system and found that piping consisted of a series of trains, and the fundamental piping frequency was approximately $350 \mathrm{~Hz}$. Wenner (1964) analyzed piping signals using a sound spectrograph, which indicated that the tooting signal begins with a long syllable and several shorter syllables with a fundamental frequency of approximately $500 \mathrm{~Hz}$, and the quacking signal is a series of short pulses with a lower fundamental frequency than tooting. Michelsen et al. (1986) measured the vibrations from tooting and quacking in the substrate of an observation hive using a laser vibrometer and, for the first time, revealed quantitative aspects of their characteristics. Tooting and quacking signals comprise a train of pulses (syllables). The first syllable of tooting lasts more than $1 \mathrm{~s}$ and is followed by a variable number of syllables lasting around $0.25 \mathrm{~s}$ each; the tooting syllables also show long rise times. Quacking comprises several syllables, each of which is less than $0.2 \mathrm{~s}$ in duration. The frequencies of both piping signals comprise one fundamental and several harmonic components. The fundamental frequency of tooting is between 350 and $500 \mathrm{~Hz}$, and a large frequency sweep is present at the beginning of each syllable. Conversely, the fundamental frequency of quacking is between 200 and $350 \mathrm{~Hz}$ and is nearly constant.

Compared with A. mellifera, it is much more difficult to investigate or even record the piping signals of A. cerana because A. cerana can easily escape from an observation hive.

Otis et al. (1995) recorded tooting sounds from an opened hive and published the spectrograms. Tooting comprised only one syllable of $4.3 \pm 2.1 \mathrm{~s}$, and there were only three frequencies of around 2.7 $\mathrm{kHz}, 3.7 \mathrm{kHz}$, and $4.5 \mathrm{kHz}$ in the spectrogram. These frequencies were very high compared with the fundamental frequency of A. mellifera tooting, and they did not show the time waveforms of tooting. Furthermore, the researchers did not record any quacking. Therefore, the acoustic characteristics of queen piping of $A$. cerana are still uncertain.

The purpose of this study was to quantitatively characterize $A$. cerana queen piping signals and to compare them with those of $A$. mellifera. We 
developed a long-term observation method through which the queen piping signals of A. cerana could be recorded with a high signalto-noise ratio in near-natural hive conditions. Honeybees respond to tooting and quacking with different behaviors (see above paragraph), although the two signals have similar fundamental frequencies. In addition, Michelsen et al. (1986) found that an artificial tooting signal without a frequency sweep induced quacking. Honeybees mainly distinguish between the two kinds of queen piping signals by making use of differences in the temporal structures, which include syllables with unique durations and intervals (Kirchner 1997; Hepburn et al., 2014). Therefore, the differences in the temporal structures of the piping signals used by the two species should be clarified so that the mechanisms of signal discrimination and the functions of queen piping can be investigated.

\section{MATERIALS AND METHODS}

\subsection{Colonies}

We used one swarm for each of the two species: A. cerana japonica and A. mellifera ligustica. In general, A. cerana japonica swarms between March and June in Japan. The experimental swarm of A. cerana, which left the parental nest in the observation field (Kawachinagano, Japan) on March 28, 2014, was trapped and kept in an empty hive box (without frames) and then the box was hung under the roof of a house. After 20 days, all walls and the floor of the box were removed, that is, only the lid was left under the roof. Using this procedure, an "artificial open nest" was built, which allowed us to make detailed observations of the "inhive" behavior of the honeybees. The observation field was in a rural area with many flowering plants and trees. Workers could forage freely, and the number of workers in the nest increased daily. Subsequently, queen cells were built and workers eventually swarmed with the mother queen at 11:00 on May 7, 2014. Figure 1a shows the artificial open nest 1 day after swarming. Altogether, there were three queen cells $(\mathrm{C} 1, \mathrm{C} 2$, and $\mathrm{C} 3)$ in the nest. The queen in cell $\mathrm{C} 1$ emerged on May 10 and the virgin queen from $\mathrm{C} 1$ left with an afterswarm at 09:30 on May 14. The queen in C2 emerged on May 14. Cell C3 was destroyed, and the queen in $\mathrm{C} 3$ was killed. The A. mellifera nest was installed in a Langstroth-type hive at the apiculture company (Akitayahonten Co. Ltd., Gifu, Japan) and set in the observation field of the School of Human Science and Environment, University of Hyogo (Himeji, Japan), in March 2018. The observation field contained many flowering plants. The number of workers in the nest increased and several queen cells were built. Workers swarmed with the mother queen, after which the workers and virgin queens left the nest in several afterswarms (not recorded). Eventually, one surviving queen took over the parental nest.

\subsection{Sound recording}

The queen piping signals of $A$. cerana were recorded using a $10-\mathrm{mm}$ diameter FM wireless condenser microphone (NT-7, EK Japan, Dazaifu, Japan) and a resin pipe (10-mm inner diameter and $60-\mathrm{mm}$ length) to connect the microphone to the hive. The microphone was installed about $90 \mathrm{~mm}$ under queen cell $\mathrm{C} 2$. The distance between the cell and the top of the pipe was $30 \mathrm{~mm}$. FM radio waves were received by a commercial radio receiver, and the audio signals were digitalized by a personal computer (p6320jp, HP Japan, Tokyo, Japan) and stored on hard disk. The piping signals of A. mellifera were recorded using a $10-\mathrm{mm}$ diameter condenser microphone (ME52W, Olympus, Tokyo, Japan) through a resin pipe $(10-\mathrm{mm}$ inner diameter and $20-\mathrm{mm}$ length), which was installed at a meshed ventilation window of the hive box (unlike with A. cerana, the microphone was not placed near the queen cell). The hive sounds were recorded using an IC recorder (ICD-PX470F, Sony, Tokyo, Japan).

\subsection{Data analysis}

We analyzed the sounds made by A. cerana recorded from the day when the queen emerged from cell C1 (May 10, 2014) to the day when she left the nest (May 14, 2014). Ten tooting (emitted by the virgin queen that emerged from $\mathrm{C} 1$ ) and 10 

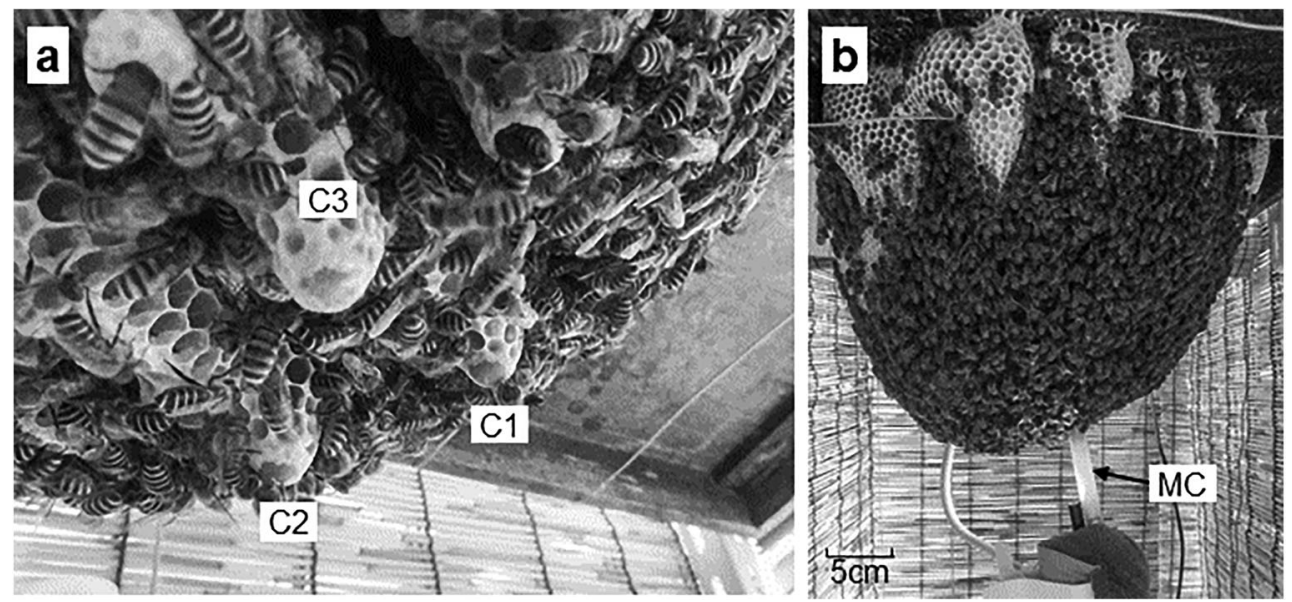

Figure 1. An artificial open nest. a There were three queen cells (C1-C3) in total on May 8, 2014, the day after mother queen swarming, and there were few worker bees because half of the worker bees had left with the mother queen at 11:00 on May 7. The queen in cell C1 emerged on May 10 and left the nest at 09:30 on May 14 in the second swarming. b View of the whole artificial open nest on May 12. The number of worker bees increased from May 8. $M C$ microphone with a resin pipe connecting it to the hive

quacking signals (emitted by the confined queen in C2) were randomly sampled from a period of frequently emitted sounds. A $150-\mathrm{Hz}$ to $5-\mathrm{kHz}$ band-pass filter was applied to each signal. The beginning and termination times of the tooting and quacking syllables were measured using the sound editing software Sound Organizer 1.6 (Sony). The following parameters were calculated for the tooting signals: the duration of a whole tooting, the number of syllables in a tooting, the duration of each syllable, the percentage duration of the first syllable to the tooting period (the duration of the first syllable divided by the duration of the whole tooting signal), and the intervals between successive syllables. The quacking signal is a train of syllables of similar duration and interval. Therefore, the following parameters were calculated for quacking: the duration of an entire quacking period, the number of syllables in a quacking, the period of the syllables (the duration of an entire quacking period divided by the number of syllables), and the duration of each syllable (calculated using one randomly sampled quacking signal). The frequencies were analyzed using FFT software, RH1FFT 3.01 (RH1 Laboratory, Japan). RH1FFT 3.01 was also used to draw the time waveforms and spectrograms.
Similarly to A. cerana, we analyzed the sounds made by $A$. mellifera recorded between May 30 and June 1, 2018 (after the prime swarm). Ten tooting and ten quacking signals were randomly sampled (the tooter and quacker could not be identified). These piping signals had a lot of background noise, such as buzzing, owing to the distance between the microphone and the piping queen. Therefore, a $700-\mathrm{Hz}$ to $5-\mathrm{kHz}$ band-pass filter was applied to the signals to increase the signal-to-noise ratio. After confirming that the filter did not affect the temporal structure by comparing two A. cerana sound waveforms through the $700-\mathrm{Hz}$ to $5-\mathrm{kHz}$ and the $150-\mathrm{Hz}$ to $5-\mathrm{kHz}$ band-pass filters, the beginning and termination times of the A. mellifera syllables were measured. Then, the temporal parameters described above were calculated using the same methods for the piping signals of A. cerana .

\subsection{Statistical analyses}

Before performing statistical analyses, normality testing of the data was performed using the Jarque-Bera test for all temporal parameters. Because the number of tooting syllables did not follow a normal distribution, the Wilcoxon rank sum test was used. For other temporal parameters 
that followed a normal distribution, the Welch's $t$ test was used.

\section{RESULTS}

\subsection{Tooting signal}

Using the surveying data for A. cerana, we determined that tooting began about 1 day before swarming, the occurrence of which increased to around 10 times every $10 \mathrm{~min}$ for approximately $6 \mathrm{~h}$ before swarming and stopped after swarming. The tooting signal began with a very long syllable followed by extremely short syllables with small amplitudes (Figure 2a). The long syllable had about $0.5 \mathrm{~s}$ of rising time. All tooting signals had the same temporal structure, although the number of syllables (including null) and the duration were slightly varied (details are described later). In comparison, the tooting signal of $A$. mellifera comprised a long syllable followed by short syllables (Figure 2b), the difference between the first syllable and the following syllables was smaller than in A. cerana . Each syllable had a rising time. All the tooting signals of $A$. mellifera also had the temporal structure shown in Figure $2 b$.

The temporal structures of the two species' signals were quantitatively compared. There was no significant difference between the two species (two-tailed $t$-test, $p=0.077$ ) with regard to the duration of a whole tooting: A. cerana lasted $4.30 \pm 0.83 \mathrm{~s}$ and A. mellifera lasted $4.98 \pm 0.79 \mathrm{~s}$ (mean \pm SD) (Figure 3a). However, there were significantly fewer syllables in the tooting of A. cerana (median 2.0) (Wilcoxon signedrank test, $p<0.001)$ compared with that of A. mellifera (7.5 syllables) (Figure $3 b$ ). Furthermore, the first syllable in A. cerana was very long $(4.04 \pm 0.67 \mathrm{~s})$ and the others were extremely short $(0.06 \pm 0.03 \mathrm{~s})$ (mean $\pm \mathrm{SD}$ after the second syllable) (Figure $3 \mathrm{c}$ ), while the first syllable in A. mellifera was $2.10 \pm$ $0.34 \mathrm{~s}$ and the following syllables had durations from $0.43 \pm 0.09 \mathrm{~s}$ (mean $\pm \mathrm{SD}$ in the second syllable) to $0.15 \pm 0.06 \mathrm{~s}$ (mean $\pm \mathrm{SD}$ in the ninth syllable) (Figure 3c). The first syllable in A. cerana was significantly longer than that of A. mellifera, by more than 1.6 times (one-tailed $t$-test, $p<0.012$ ). The difference in the percentage duration of the first syllable to the entire tooting period showed even greater variation between the two species than was seen for the difference between the duration of the first syllables. The first syllable of A. cerana $(94.7 \pm 4.5 \%)$ was more than 1.7 times the length of that of A. mellifera $(42.9 \pm$ $8.4 \%$ ) (one-tailed $t$-test, $p<0.001$ ). The interval between successive syllables was also investigated. The intervals of A. cerana, 0.08 $\pm 0.05 \mathrm{~s}$, were significantly shorter than those of A. mellifera, $0.18 \pm 0.04$, (mean $\pm \mathrm{SD}$ ) (one-tailed $t$-test, $p<0.002$ ) (Figure 3d).

Michelsen et al. (1986) reported that a large frequency sweep was present at the beginning of the tooting syllables of $A$. mellifera and was characteristic of the tooting signal. A sweep from 375 to $410 \mathrm{~Hz}$ in the fundamental frequency was also present in the first $1 \mathrm{~s}$ of the first syllable of A. cerana (Figure 4b, black bar).

\subsection{Quacking signal}

Quacking of A. cerana also began around 1 day before swarming; the occurrence increased to around 10 times per $10 \mathrm{~min}$ for approximately $6 \mathrm{~h}$ before swarming, and quacking stopped after swarming. Not all, but many, quacking signals were induced by tooting. All quacking signals had the same temporal structure as is shown in Figure 5a, in which short syllables continued at a constant period. All quacking signals of A. mellifera also comprised many short syllables with a constant period (Figure $5 b$ ).

We compared the temporal parameters, and although the number of syllables varied widely, there was no significant difference between A. cerana (46.9 \pm 15.4$)$ and A. mellifera $(49.3 \pm$ 15.3) (Figure 6a, two-tailed $t$-test, $p=0.73$ ). However, the duration of an entire quacking period of $A$. cerana $(7.85 \pm 2.39 \mathrm{~s})$ was significantly shorter than that of A. mellifera $(19.2 \pm 6.12 \mathrm{~s})$ (Figure 6b, one-tailed $t$-test, $p<0.0001)$. The period of the syllables in A. cerana $(0.17 \pm 0.01$ s) was less than half of that in A. mellifera $(0.39 \pm$ $0.01 \mathrm{~s}$ ) (Figure 6c, one-tailed $t$-test, $p<0.0001$ ). The durations of each syllable in A. cerana and A. mellifera were $0.07 \pm 0.01 \mathrm{~s}(n=61)$ and 0.17 
a

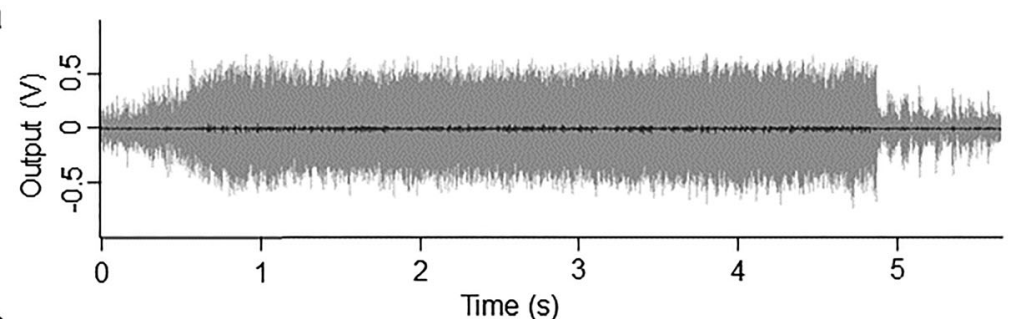

b

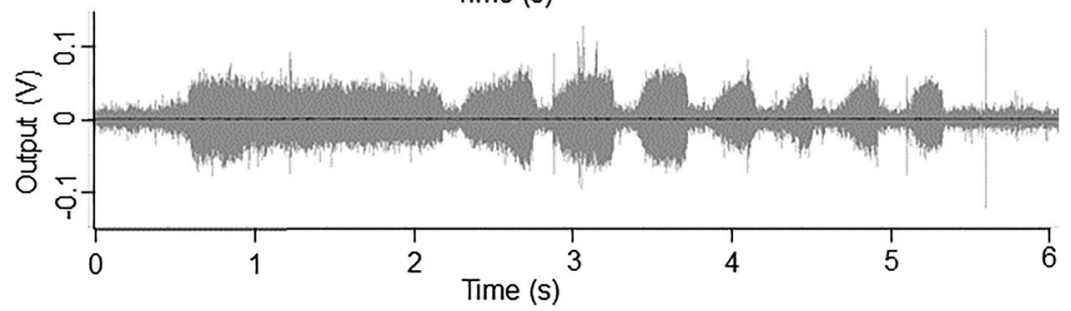

Figure 2. Time waveform of representative tooting. a Tooting signal of A. cerana after passing through the $150-\mathrm{Hz}$ to 5-kHz band-pass filter; the signal comprised a long syllable of around $4 \mathrm{~s}$ and some smaller syllables shorter than $0.1 \mathrm{~s}$. The long syllable had an approximately $0.5 \mathrm{~s}$ rise time. b Tooting signal of $A$. mellifera after passing through the $700-\mathrm{Hz}$ to $5-\mathrm{kHz}$ bandpass filter; the signal comprised a long syllable of around $2 \mathrm{~s}$ followed by short syllables. Each syllable had a rising time

A.cerana

b

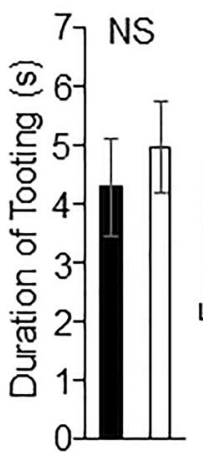

Species

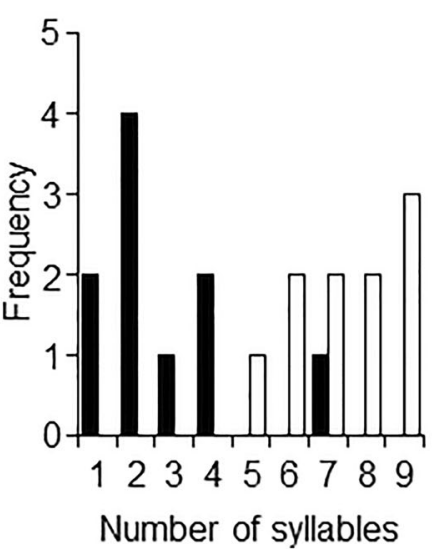

Number of syllables
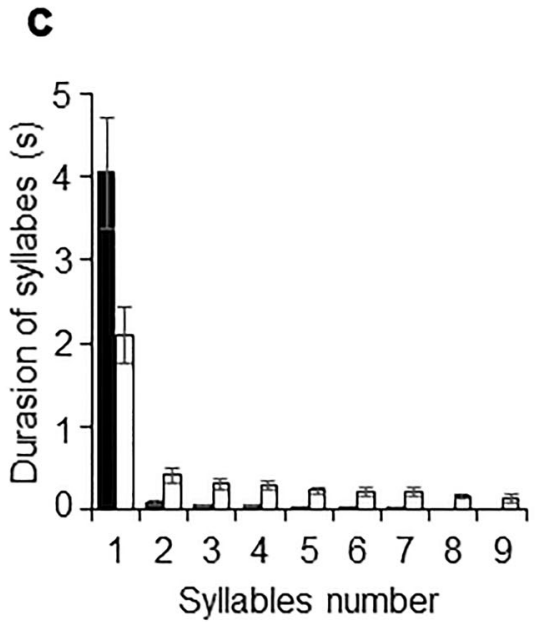

A.mellifera

d

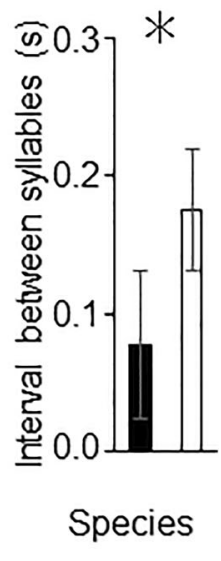

Figure 3. Temporal parameters of tooting in the two species. The black and white bars indicate A. cerana and A. mellifera, respectively. a Duration of a whole tooting. A. cerana lasted $4.30 \pm 0.83 \mathrm{~s}$, and A. mellifera lasted $4.98 \pm 0.79 \mathrm{~s}($ mean $\pm \mathrm{SD})$. There was no significant difference between the two species. b Histogram of the number of syllables; the median syllable numbers were 2.0 for A cerana and 7.5 for A. mellifera. c Duration of each syllable; the mean duration (seconds $\pm \mathrm{SD}$ ) of the first syllable of $A$. cerana $(4.04 \pm 0.67)$ was longer than of A. mellifera $(2.10 \pm 0.34)$; the mean percentage $( \pm \mathrm{SD})$ duration of the first syllable to the tooting period of A. cerana $(94.7 \pm 4.5 \%)$ was much longer than that of A. mellifera $(42.9 \pm 8.4 \%)$. d Interval between successive syllables; A. cerana , $0.08 \pm 0.05 \mathrm{~s}$, were significantly shorter than those of A. mellifera, $0.18 \pm 0.04$, (mean $\pm \mathrm{SD}$ ). Asterisk: significant difference $(p<0.002), N S$ no significant difference 


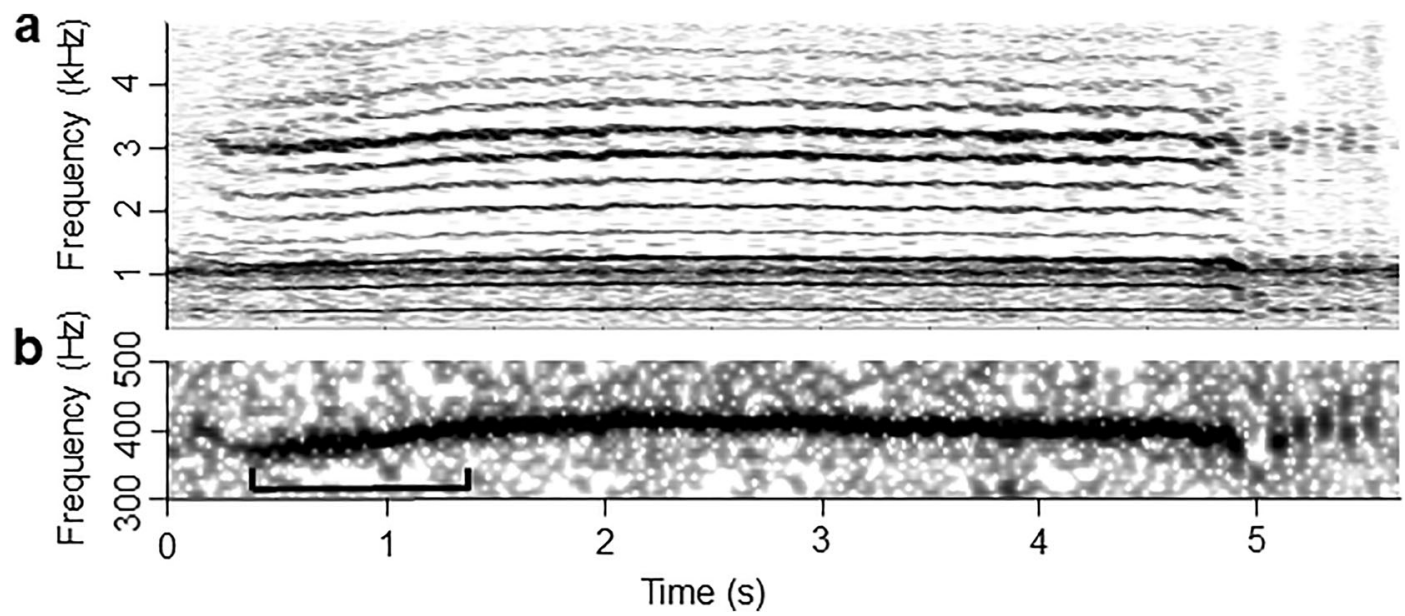

Figure 4. Spectrogram of representative tooting of A. cerana. a The tooting sound comprised a fundamental frequency (around $400 \mathrm{~Hz}$ ) and many harmonics. b Expanded spectrogram between 300 and $500 \mathrm{~Hz}$; a frequency sweep from 375 to $410 \mathrm{~Hz}$ is present during the first $1 \mathrm{~s}$ of the first syllable (black bar)

$\pm 0.03 \mathrm{~s}(n=31)$, respectively (Figure $6 \mathrm{~d})$. The duration of each syllable of $A$. cerana was also less than half of that of $A$. mellifera (one-tailed $t$ - test, $p<0.0001)$. Consequently, the duration of an entire quacking period of $A$. cerana was less than half of that of $A$. mellifera because the

a
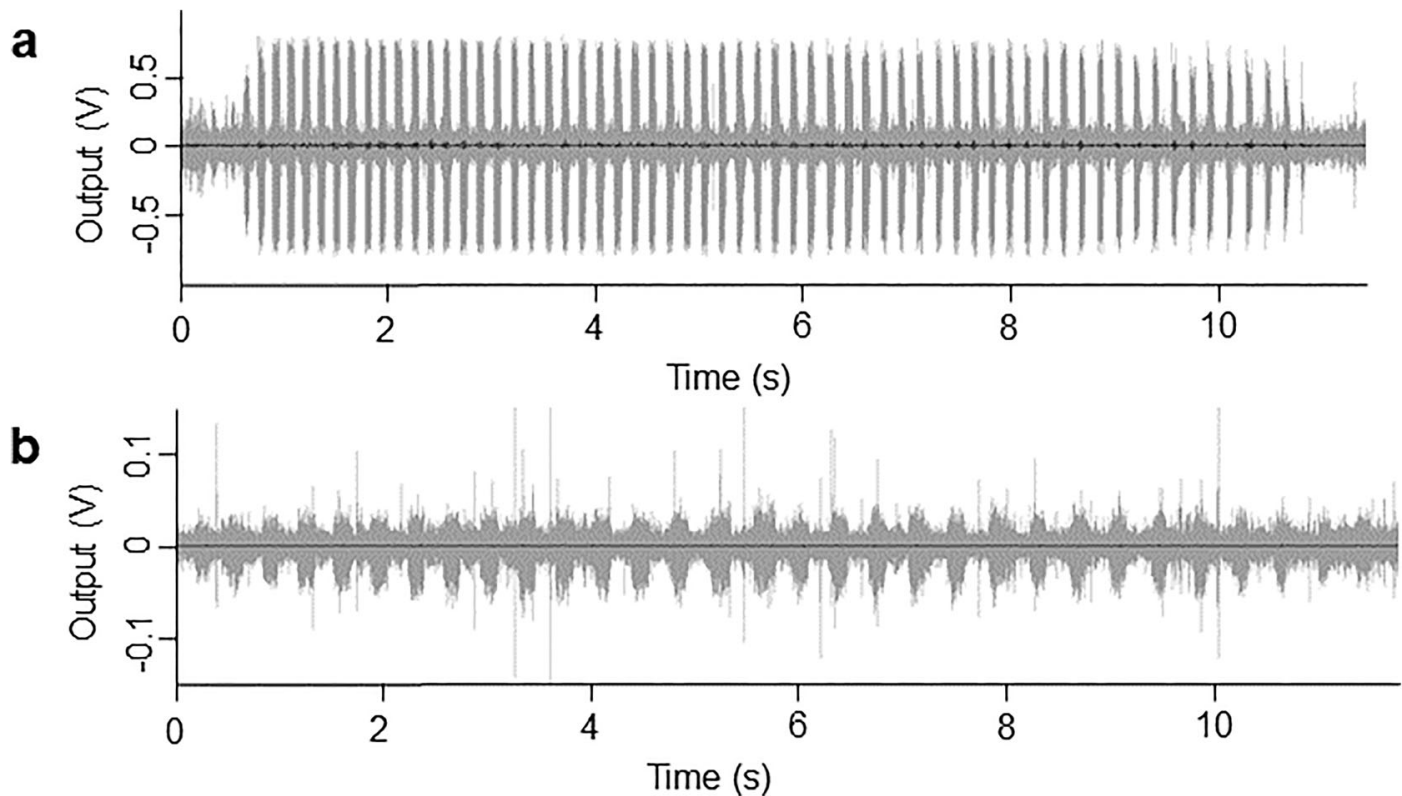

Figure 5. Time waveform of representative quacking. a Quacking signal of A. cerana after passing through the $150-\mathrm{Hz}$ to $5-\mathrm{kHz}$ band-pass filter; the signal comprised short syllables with a constant period. b Quacking signal of A. mellifera after passing through the $700-\mathrm{Hz}$ to $5-\mathrm{kHz}$ band-pass filter. The signals of both species comprised many short syllables with a constant period, but the tempo of A. cerana quacking was faster than that of A. mellifera 
A.cerana

b NS

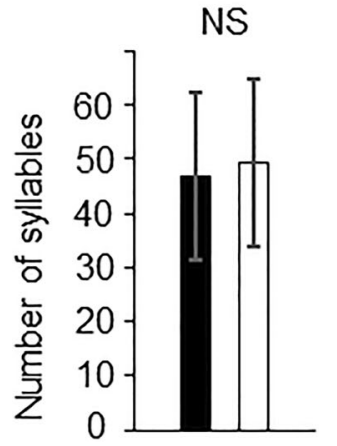

*

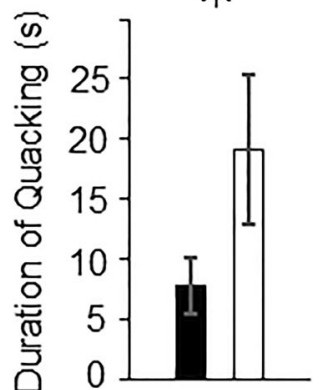

C

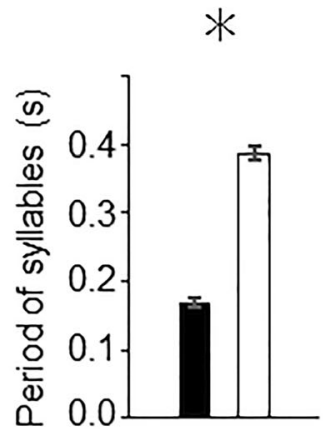

$\square$ A.mellifera

d

Figure 6. Temporal parameters of quacking in the two species. The black and white bars indicate A. cerana and A. mellifera, respectively. a Number of syllables; there was no significant difference between the two species. Error bars indicate standard deviations. b Duration of an entire quacking period; the mean duration (seconds $\pm \mathrm{SD}$ ) of A. cerana $(19.2 \pm 6.12)$ was significantly shorter than that of A. mellifera $(7.85 \pm 2.39)$, that is, less than half. c Period of syllables; the mean period (seconds $\pm \mathrm{SD})$ of $A$. cerana $(0.17 \pm 0.01)$ was significantly shorter than that of A. mellifera . $(0.39 \pm 0.01)$, that is, less than half. d Duration of a single syllable; the mean duration (seconds $\pm \mathrm{SD}$ ) of A. cerana $(0.07 \pm 0.01, n=61)$ was also significantly shorter than that of $A$. mellifera $(0.17 \pm 0.03, n=31)$, that is, less than half. Asterisk: significant difference $(p<0.0001), N S$ no significant difference

syllable periods and durations of A. cerana quacking were less than half of those for A. mellifera, although the numbers of syllables were comparable.

\section{DISCUSSION}

Michelsen et al. (1986) and Kirchner (1993) measured the piping signals of $A$. mellifera carnica queens using a laser vibrometer. They reported that the tooting signal comprised a first syllable lasting over $1 \mathrm{~s}$ and other syllables of around $0.25 \mathrm{~s}$, and the signal was characterized by a frequency sweep and a rise in amplitude at the beginning of each syllable. In the present study, we used another subspecies, A. mellifera ligustica, and found that its tooting signals had the same temporal structures and characteristics (a frequency sweep was confirmed by listening to the sounds) as those of $A$. mellifera carnica (Fig. $2 b)$. The tooting signal of $A$. cerana certainly had the same characteristics (a frequency sweep and a rise in amplitude at the beginning of the syllable) as A. mellifera carnica, but its temporal structures differed (Fig. 2). There were very few syllables in the tooting of A. cerana (Figure 3b). Furthermore, the percentage duration of the first syllable to the tooting period was much higher than that of A. mellifera ligustica (Figure 3c).

Otis et al. (1995) reported that the tooting of A. cerana comprised only one syllable of $4.3 \pm$ $2.1 \mathrm{~s}$ (mean $\pm \mathrm{SD}$ ) and that it had three frequencies of approximately $2.7 \mathrm{kHz}, 3.7 \mathrm{kHz}$, and $4.5 \mathrm{kHz}$. The measured sounds may have had only one syllable and very high frequencies for the following possible reasons: (1) it is difficult to measure the succeeding syllables because the amplitudes are very small and the duration extremely short (Figure $2 \mathrm{a}$ ) and $20 \%$ of tooting has only one syllable (Figure $3 b$ ) and (2) it is difficult to measure the lower frequencies because the higher frequency sounds are amplified more than the lower frequency sounds in the hive (Michelsen et al. 1986).

Michelsen et al. (1986) and Kirchner (1993) also reported that the quacking signal of A. mellifera carnica comprised several syllables that were shorter than $0.2 \mathrm{~s}$. The quacking signals of A. mellifera ligustica and A. cerana had the same temporal structures, but the tempo of 


\section{Tooting}

\section{A. mellifera}

Quacking

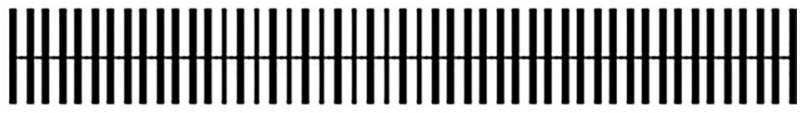

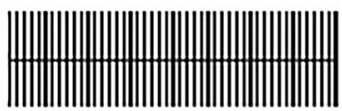

\section{$1 \mathrm{~s}$}

Figure 7. Schematic of the temporal patterns of tooting and quacking of A. mellifera and A. cerana from our results. The amplitudes of all syllables were set to 1 for convenience. The definitive difference between tooting and quacking is the length of the first syllable. Indeed, the temporal structure of A. mellifera tooting after the second syllable is similar to the temporal structure of A. mellifera quacking. However, the second and subsequent syllables of A. cerana tooting are extremely short

A. cerana was different. The period and the duration of the syllables were much less than half those of A. mellifera (Figure 6c, d).

The temporal structure of a signal has an important role in sound and vibration communications in many animals. Courtship and calling songs have different temporal structures in stink bugs, Drosophila, and Ensifera, (Ewing 1983; Bennet-Clark 1989; Čok1 2008). In both A. mellifera and A. cerana, the definitive difference between tooting and quacking is the length of the first syllable, which is a great deal longer in tooting than in quacking (Figure 7). However, Michelsen et al. (1986) found that an artificial tooting signal, which had a similar temporal structure to A. mellifera tooting after the second syllable, that is, six syllables with an approximate duration of $0.25 \mathrm{~s}$ and period of $0.5 \mathrm{~s}$, induced quacking. The period of A. mellifera's tooting after the second syllable was $0.43 \pm 0.06 \mathrm{~s}$, which is not significantly different from the period of
A. mellifera quacking, that is, $0.39 \pm 0.01 \mathrm{~s}$ (twotailed $t$-test, $p=0.072$ ). In addition, when one queen starts quacking, other queens will gradually join the "quacking concert" (Michelsen et al. 1986). Therefore, queens who emit quacking in response to an artificial signal might perceive the signal to be quacking. It would be interesting to conduct an experiment to verify if one long syllable of a tooting signal induces quacking in the two species.

The queen quacks when she is in her cell, and she changes her signal to tooting after emerging. She produces a tooting signal by activating the wing muscles without wing movement while grasping and pressing her thorax against a substrate (Kirchner 1993, Hunt and Richard 2013). When she is in her cell, it is likely that she cannot grasp a substrate and press her thorax against it, as a result, she activates her muscles in a pulsating manner and produces a train of pulsing

Table I. Comparison of piping temporal parameters of A. cerana, A. koschevnikovi, and A. mellifera (mean \pm SD)

\begin{tabular}{|c|c|c|c|}
\hline Species & $\begin{array}{l}\text { Duration of the first syllable } \\
\text { in a tooting }(\mathrm{s})\end{array}$ & $\begin{array}{l}\text { Percentage duration of the first syllable to } \\
\text { the tooting period }(\%)\end{array}$ & $\begin{array}{l}\text { Period of syllables in a } \\
\text { quacking (s) }\end{array}$ \\
\hline
\end{tabular}

\begin{tabular}{llll}
\hline A. cerana & $4.04 \pm 0.67$ & $94.7 \pm 4.8$ & $0.17 \pm 0.01$ \\
${\text { A. } \text { koschevnikovi }^{*}}^{*} 4.3 \pm 0.6$ & 100 & 0.23 \\
A. mellifera & $2.04 \pm 0.34$ & $42.9 \pm 8.4$ & $0.39 \pm 0.01$
\end{tabular}

* The parameters of A. koschevnikovi are from Otis et al. (1995) 
vibrations, that is, quacking, because of the difficulty of continuous activation without using her legs to support her body. This hypothesis could be tested by observing whether an emerged queen reverts to emitting quacking signals when she is re-confined within a queen cell. Furthermore, in our measurements, the frequency of occurrence of short syllables after the first long syllable in A. cerana tooting tended to decrease with time after emergence. From this, we postulated that these short syllables might be a relic of quacking.

A quantitative comparison of the temporal parameters should provide some insights into the evolution of queen piping. Some possible key parameters (the duration of the first syllable of tooting, the percentage duration of the first syllable to the tooting period, and the period of syllables in quacking) of three cavity-nesting honeybees A. cerana, A. koschevnikovi, and A. mellifera are shown in Table I. When a phylogenic tree was constructed using mitochondria DNA, it showed that A. mellifera is distant from both A. cerana and A. koschevnikovi (Arias and Sheppard 2005). The temporal parameters of A. cerana and A. koschevnikovi are very similar, while those of $A$. mellifera differ from the others. Moreover, in A. cerana and A. koschevnikovi, tooting is clearly different from quacking; however, A. mellifera tooting is similar to its quacking, that is, the first syllable of tooting is short and the subsequent syllables after the second syllable are similar to quacking (Figure 7). Queens and workers distinguish between the two kinds of signals mainly via differences in the temporal structure (Kirchner 1997; Hepburn et al. 2014). Therefore, it would be interesting to investigate why these differences evolved between A. mellifera and the group containing A. cerana and $A$. koschevnikovi .

\section{ACKNOWLEDGMENTS}

The authors thank Suzanne Leech Ph.D., from Edanz Group (https://en-authorservices.edanz.com/ac) for editing a draft of this manuscript.

\section{AUTHOR CONTRIBUTION}

TY, MS, RO, and HI conceived this research and wrote the paper. TY designed and performed the experiments and analyzed all data. TY, MS, RO, and $\mathrm{HI}$ interpreted the data. TY, RO, and HI read and approved the final manuscript.

\section{DATA AVAILABILITY}

The datasets generated during and/or analyzed during the current study are available from the corresponding author on reasonable request.

\section{COMPLIANCE WITH ETHICAL STANDARDS}

Competing interests The authors have no conflicts of interests to declare that are relevant to the content of this article.

Ethical approval Not applicable.

Différences entre les structures temporelles du chant des reines de deux espèces d'abeille, Apis cerana et Apis mellifera .

Apis cerana / reine / chant / communication / essaimage / vibroacoustique.

Unterschiede im zeitlichen Ablauf beim Tüten und Quaken von Königinnen bei zwei Arten von Honigbienen, Apis cerana und Apis mellifera.

Apis cerana / Königin / Tüten / Quaken / Kommunikation / Schwärmen / Vibrationsakustik.

\section{REFERENCES}

Arias, M.C., Sheppard, W.S. (2005) Phylogenetic relationships of honey bees inferred from nuclear and mitochondrial DNA sequence data. Mol Phylogenet Evol 37: $25-35$

Bennet-Clark, H.C. (1989) Songs and the physics of sound production, in: Huber, F., Moore, T.E., Loher, W. (eds) Cricket behavior and neurobiology. Comstock Publishing Associates, Ithaca, pp. 227-261 
Bruinsma, O., Kruijt, J.P., van Dusseldorp, W. (1981) Delay of emergence of honey bee queens in response to tooting sounds. Proc K Ned C 84: 381-387

Čokl, A. (2008) Stink bug interaction with host plants during communication. J Insect Physiol 54: 11131124

Ewing, A.W. (1983) Functional aspects of Drosophila courtship. Biol Rev 58 : 275-292

Fletcher, D.J.C. (1978) Vibration of queen cells by worker honeybees and its relation to the issue of swarms with virgin queens. J Apicult Res 17(1) : 14-26

Gilley, D.C. (2001) The behavior of honey bees (Apis mellifera ligustica) during queen duels. Ethology 107: 601-622

Gilley, D.C., Tarpy, D.R. (2005) Three mechanisms of queen elimination in swarming honey bee colonies. Apidologie 36 : 461-474

Grooters H.J. (1987) Influences of queen piping and worker behavior on the timing of emergence of honey bee queens. Insecte Soc Paris 34 : 181-193

Grozinger, C.H., Richard, J., Mattila, H.R. (2014) From molecules to societies: Mechanisms regulating swarming behavior in honey bee (Apis spp.). Apidologie $45: 327346$

Hepburn, H.R., Pirk, C.W.W., Duangphakdee, O. (2014) Communication by vibrations and scents in the comb, in: Honeybee nests. Springer, Berlin, Heidelberg, pp. 79-103

Hrncir, M., Barth, F.G., Tautz, J. (2005) Vibratory and airborne-sound signals in bee communication, in: Drosopoulos, S., Claridge, M.F. (eds) Insect sounds and communication: physiology, behaviour, ecology and evolution. CRC Press Taylor and Francis, Boca Raton, pp. 421-436

Huber, F. (1792) Nouvelles observations sur les abeilles. Paschoud, Geneva

Hunt, J.H., Richard, F.J. (2013) Intracolony vibroacoustic communication in social insects. Insecte Soc 60 : 403417

Kirchner, W.H. (1993) Acoustical communication in honeybees. Apidologie 24 : 297-307

Kirchner, W.H. (1997) Acoustical communication in social insects, in: Lehrer, M. (ed) Orientation and communication in Arthropods. Birkhäuser, Basel, pp. 273-300

Long, K., Cao, T.T., Keller, J.J., Tarpy, D.R., Shin, M., Schneider, S.S. (2017) Levels of selection shaping caste interactions during queen replacement in the honey bee, Apis mellifera. Insecte Soc 64 : 227-240

Michelsen, A., Kirchner, W.H., Andersen, B.B., Lindauer, M. (1986) The tooting and quacking vibration signals of honeybee queens: A quantitative analysis. J Comp Physiol A 158: 605-611

Nieh, J.C. (2010) A negative feedback signal that is triggered by peril curbs honey bee recruitment. Curr Biol 20 : $310-315$

Otis, G.W., Patton, K., Tingek, S. (1995) Piping by queens of Apis cerana Fabricus 1793 and Apis koschevnikovi v Buttel-Reepen 1906. Apidologie 26: 61-65

Schneider, S.S., Painter-Kurt, S., DeGrandi-Hoffman, G. (2001) The role of the vibration signal during queen competition in colonies of the honeybee, Apis mellifera. Anim Behav 61 : 1173-1180

Schneider, S.S., DeGrandi-Hoffman, G. (2003) The influence of paternity on virgin queen success in hybird colonies of European and African honeybees. Anim Behav 65 : 883-892

Schneider, S.S., Lewis, L.A. (2004) The vibration signal, modulatory communication and the organization of labor in honey bee. Apidologie 35 : 117-131

Seeley, T.D., Tautz, J. (2001) Worker piping in honey bee swarms and its role in preparing for liftoff. $\mathrm{J}$ Comp Physol A 87 : 667-676

Seeley, T.D., Visscher, P.K., Schlegel, T., Hogan, P.M., Franks, N.R., Marshall, J.A.R. (2012) Stop signals provide cross inhibition in collective decision-making by honeybee swarms. Science 335 : 108-111

Smith, M.L., Ostwald, M.M., Loftus, J.C., Seeley, T.D. (2014) A critical number of workers in a honeybee colony triggers investment in reproduction. Naturewissenschaften, 101: 783-790

Tan, K., Dong, S., Li, X., Liu, X., Wang, C., Li, J., Nieh, J.C. (2016) Honey bee inhibitory signaling is tuned to threat severity and can act as a colony alarm signal. PLOS Biology 14: e1002496. https://doi.org/10.1371 /journal.pbio.1002496

Visscher, P.K. (1993) A theoretical analysis of individual interests and intracolony conflict during swarming of honey bee colonies. J Theor Biol 165 : 191-212

Wenner, A.M. (1964) Sound communication in honeybees. Sci Am 210 : 116-124

Winston, M.L. (1987) The biology of the honey bee. Harvard University Press, Cambridge, London, pp. 181198

Woods, E.F. (1956) Queen piping. Bee World 10: 185$195,216-219$

Publisher's note Springer Nature remains neutral with regard to jurisdictional claims in published maps and institutional affiliations. 